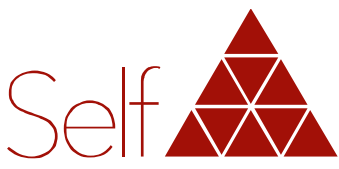

Revista do Instituto Junguiano de Säo Paulo

\title{
O falar da alma nas disfunções sexuais
}

\section{M arisa Horta IM PERATRICE}

São Paulo, SP, Brasil.

\section{Resumo}

Este trabalho representa uma proposta na busca por uma interação entre sintoma e psique, uma tentativa de ir para além do corpo - sede da dificuldade física - na direção do encontro com a alma. $\bigcirc$ que a alma quer de mim? $\bigcirc$ que aquilo que é mais profundo em mim deseja com esse sintoma? Se negligenciada, a alma não apenas vai embora: os sintomas surgem, a neurose é a sua fala. Querer afastar os conflitos só faz com que eles se aproximem mais, pois é de sua natureza se expressarem em nós e em nossos sintomas. Buscar o significado de grandezas como a psique e o sexo ocupa o mesmo lugar de querer explicar o amor, a beleza, a vida, a morte ou Deus. Para nos aproximarmos disso, recorremos a padrões míticos que ampliem o olhar sobre uma sexualidade que se encontra bloqueada e necessitada de integração, entrelaçando conceitos da psicologia analítica sob uma vertente arquetípica. $\bigcirc$ objetivo é restabelecer um sentido de alma por meio do encontro sexual.

\section{Descritores}

sexo, sexualidade, distúrbios da função sexual, individuação.

Conflito de interesses:

A autora declara não haver nenhum interesse profissional ou pessoal que possa gerar conflito de interesses em relação a este manuscrito.

Recebido: 24 maio 2016; $1^{\text {a }}$ revisão: 14 jul 2016; $2^{\text {a }}$ revisão: 27 jul 2016; Aprovado: 15 set 2016; Aprovado para publicação: 27 out 2016. 


\title{
The talk of the soul in sexual dysfunctions
}

\begin{abstract}
This work represents a proposal to search an interaction between symptom and psyche, an attempt to go beyond the body - seat of the physical difficulty - toward an encounter with the soul. What does the soul want from me? What does the deepest part in me demand with this symptom? If neglected, the soul not only goes away: symptoms arise, neurosis is its speech. Wanting to ward off conflicts only makes them to come closer, because it is part of their nature to express themselves in us and in our symptoms. Seeking for the meaning of nobilities like psyche and sex is the same of intending to explain love, beauty, life, death and God. To get closer to it, we turn to mythic patterns that enhance a look at a locked sexuality that needs integration, linking concepts of analytical psychology in an archetypal perspective. The goal is to restore a sense of soul through the sexual encounter.
\end{abstract}

\section{Descriptors}

sex, sexuality, sexual function disturbances, individuation.

\section{El hablar del alma en las disfunciones sexuales}

\section{Resumen}

Este trabajo representa una propuesta en la búsqueda de una interacción entre el síntoma y la psique, un intento por ir más allá del cuerpo - sede de la dificultad física - hacia el encuentro con el alma. ¿Qué quiere el alma de mí? ¿Qué desea con este síntoma aquello que es lo más profundo en mí? Si se descuida, el alma no simplemente desaparece: surgen síntomas, la neurosis es su discurso. Querer evitar los conflictos solo hace que ellos se acerquen más, porque es su naturaleza expresarse en nosotros y en nuestros síntomas. Buscar el significado de grandezas como la psique y el sexo está en el mismo lugar de querer explicar el amor, la belleza, la vida, la muerte o Dios. Para aproximarnos a esto, recurrimos a patrones míticos que mejoren la mirada de una sexualidad que se encuentra bloqueada y necesitada de integración, entrelazando conceptos de la psicología analítica bajo una vertiente arquetípica. El objetivo es restablecer un sentido de alma a través del encuentro sexual.

\section{Descriptores}

sexo, sexualidad, trastornos de la función sexual, individuación. 


\section{Introdução}

Eu, tua alma, sou tua mãe, envolvendo-te com carinho e medo. Tua nutridora e destruidora, prepara-te coisas boas e veneno. Sou tua intercessora [...] Eu te ensino os artifícios que te protegem [...] Eu sou teu corpo, teu representante no mundo dos deuses, teu brilho, tua respiração, teu cheiro, tua força mágica. (Jung, 2013, pp. 515-516)

Onde se unem sexo, disfunção e alma? Talvez essa união se encontre em uma busca pelo sentido do sagrado que envolve as dimensões fundamentais da existência humana, sentido hoje tão desconsiderado. Esta busca não é uma busca qualquer, mas aquela individual de determinada pessoa a quem, permanecendo na alma, algo lhe é revelado: um entendimento melhor de si mesma. Buscar o aspecto sagrado do sexo aprofunda o valor que ele pode agregar à vida humana. Aqui, não há somente que se entender o problema, mas sentir sua dimensão integradora a partir dos estratos mais profundos da alma.

Procuramos aqui abordar o sexo por meio do psíquico, sobretudo quanto ao seu aspecto disfuncional, deslocando-o do lado físico - onde ele é somente um diagnóstico médico - para a totalidade do ser humano, por meio de sua alma. Fazer isso é buscar sair de lugares-comuns, tais como: "a ejaculação precoce se apresenta assim...", "a disfunção erétil ocorre dessa ou daquela forma", "o vaginismo tem essas ou aquelas características", e seguir na direção da universalidade integradora do sonho, do mito e do arquétipo.

Ao nos aprofundarmos no mundo interno dos pacientes, vemos essas disfunções em um caleidoscópio de formas, contextos, emoções e sensações, que, em última análise, são sempre simbólicas do que está na alma da pessoa. Thomas Moore (2009) afirma: "A alma tem algo de frio e líquido, quente e ígneo." (p. 44) O sexo é um sistema de símbolos na vida humana como nenhum outro. É por meio dele que a perpetuação da raça humana se realiza.

\section{Polo estruturante de nossa identidade}

O sexo como parte da vida humana - certamente, boa parte dela - desperta nossa atenção desde os primórdios da nossa existência. É um acontecimento que possibilita a intercomunicação da pessoa consigo mesma e com o outro. O sexo é um dos polos estruturantes da nossa identidade e envolve o encontro com o outro. É nele que interagem a nossa história de vida e a do(a) nosso(a) parceiro(a). É nesse encontro que as nossas inseguranças naturalmente estão presentes, tornando a ligação não apenas um ato físico, mas uma intimidade onde o que somos se revela. Como ensina Moore (1996): "O sexo é o espelho límpido da alma, revelando-a em seus gestos." (p. 224) O sexo é também uma arte e para tanto requer certa perícia. Mas o sexo vai muito além do encontro físico. Possui uma complexidade maior. Abarca o biológico, o psíquico e o religioso. Então, a pessoa, ao interagir 
sexualmente, se confronta com o seu potencial físico, com a sociabilização, e ainda terá de se envolver com os seus valores culturais e crenças religiosas. Podemos dizer que essa pessoa, sem perceber, está em um caldeirão em ebulição quando o sexo quer se manifestar. Alguns conseguem interagir sem maiores problemas, outros, ao viver um conflito, desencadeiam sintomas.

As questões que envolvem a sexualidade foram seriamente estudadas apenas muito recentemente. Somente a partir do princípio do século XX o comportamento sexual foi mais amplamente pesquisado e muito devemos, nessa questão, a Sigmund Freud, Alfred Kinsey, William Master, Virginia Johnson e Helen Kaplan, dentre outros.

No mundo atual, sexo não é mais propriamente um tabu. Dele se fala em qualquer esquina. Diz-se abertamente o que se faz na cama, e tenta-se resolver os seus mistérios colocando-o em praça pública, desmitificando o seu poder, desalmando-o. Ao retirar dele a alma, o que sobra é apenas o corpo enquanto matéria, que inevitavelmente paga um preço por isso. Por mais que se fale livremente em sexo e por mais educação sexual que se ministre, meninas e meninos continuam engravidando inadvertidamente, e homens e mulheres adultos continuam apresentando problemas nessa esfera da existência. Como esse corpo que expressa um sintoma e essa alma adormecida e desconsiderada podem encontrar um campo de conciliação? Como aconselha Thomas Moore (2009): "Devemos retornar ao corpo mitológico, sutil, cheio de fantasias, da imaginação. $\bigcirc$ corpo e o espírito se casando na capela da alma." (p. 41)

O sexo é parte fundamental da vida humana, na qual se alojam profundos mistérios; como a psique se revela por meio de imagens simbólicas carregadas de emoção, as disfunções sexuais podem ser compreendidas como imagens que a alma escolhe para despertar as pessoas para o cultivo de si mesmas. Olhar a alma de perto por vezes desperta sentimentos de vergonha, apreensão, medo, perplexidade e até de desesperança. Jung (2002) afirma que alma é como a prima matéria da alquimia:

A prima matéria é [...] de pouco valor e se encontra em toda parte, só que ninguém a conhece. Ela também é esquiva e vaga, tal como a lapis que se produz a partir dela; ela tem mil nomes. p pior é que sem ela a obra não pode nem iniciar-se. (p. 171; OC XIII, 209)

\section{Disfunções sexuais, doenças da alma}

Não cabe aqui dar explicações técnicas ou clínicas detalhadas a respeito das disfunções sexuais. Para quem deseja se aprofundar, indica-se o livro "Heterossexualidade" de William Master, Virginia Johnson e Robert Kolodny (1997). Um casal pode passar por momentos delicados, nos quais a falta de desejo venha a se colocar, mas isto só é visto como disfunção quando esse fator se torna constante: o que caracteriza uma disfunção sexual, seja no homem, seja na mulher, é sua permanência durante meses consecutivos, 
fora da fase de iniciação sexual, e desde que a pessoa não esteja atravessando uma crise no relacionamento. Quase invariavelmente, quando a disfunção ocorre em um dos parceiros, o outro também mostra alguma dificuldade. Vale ressaltar que as dificuldades com a sexualidade não surgem somente em relações heterossexuais: a psique não se atém a gênero ou orientação sexual.

No entanto, devido à complexidade orgânica relativa aos gêneros, existem diferenças entre as dificuldades sexuais masculina e feminina. No homem podemos encontrar problemas ejaculatórios, tais como a ejaculação precoce e a ejaculação retardada. Com relação à questão da ereção, esta é vista como disfuncional quando há um quadro constante relacionado a ter ou a manter a ereção. As dificuldades sexuais femininas, por sua vez, são observadas em problemas relativos ao orgasmo, à dispareunia e ao vaginismo. Dispareunia é desconforto ou mesmo dor persistente e constante, no início, durante e/ou logo após o fim do ato sexual, sendo-lhe o vaginismo - a contração involuntária dos músculos da vagina - tanto causa como consequência. Em casos graves, pode impedir totalmente a penetração do pênis.

Sexo vem de secare, que em latim significa separar, cortar. Alma e sexo têm algo em comum contido nessas palavras: separam e cortam. $\bigcirc$ sexo nos separa em homens e mulheres, nos corta ou divide e nos deixa incompletos, criando a busca pelo outro. A alma aparece separada de nós, mas contida em nós, e pode ser cortada de sua base instintiva.

Na nossa era, Eros, filho de Afrodite e amante de Psique, deus que simboliza o sexo e a sexualidade, somente é lembrado pela palavra "erótico": o que talvez reste desta divindade, o aspecto carnal prevalecendo. Como lembra Jung, um deus excluído vira doença. Esse deus é o elo entre nós e a alma: aquele que faz a conexão entre o físico e o emocional. Eros quer permear a alma e nos lega dessa união a volúpia, o prazer sexual, o prazer dos sentidos, o prazer em geral.

Afrodite, mãe de Eros, é uma deusa antiga, da linhagem da Grande Mãe, única filha nascida da essência imortal de Urano, do esperma que the caiu ao mar após ele ter sido esquartejado por Cronos: mar que é encarnação da emoção, do inconsciente, lugar que rejeita grilhões: não importa o que digamos sobre ele, sempre haverá algo nele que não conseguimos descrever. Segundo Plotino, filósofo neoplatônico, Afrodite anseia pela união conosco e, apesar de exigir enormes tarefas, nos leva a Eros, que serve a alma que anseia ser trabalhada e busca nas relações sexuais um motivo para isso. É no encontro com o outro - no atritar das relações - que reside a possibilidade de se encontrar com a própria alma. Em Afrodite encontramos a sexualidade que nos estimula a olhar a beleza, a beleza de um pôr do sol, de uma flor ou de um corpo bonito, o afrodisíaco que, se não estiver presente, faz a vida perder prazer e beleza, o sexo restando oco.

$\bigcirc$ medo que temos dos sentimentos e das emoções que o sexo provoca em nós está muito próximo do medo que sentimos em relação às coisas da 
psique de modo geral. Ambos nos tiram da vida segura e estável que almejamos e nos lançam a um turbilhão de vivências. Viver a vida com sexualidade é vivê-la eroticamente. A alma - podemos dizer - é erótica, pois está sempre desejando algo.

Relatamos aqui pesquisa realizada no Brasil em 2000, que abrangeu do Oiapoque ao Chuí, patrocinada pelo Laboratório Pfizer quando da implantação do medicamento para impotência masculina, o Viagra, e que deu origem ao livro "Descobrimento sexual do Brasil". Nela, apurou-se que:

$O$ (a) brasileiro(a) tem uma série de receios diante do sexo, mas os medos sexuais masculinos atingem índices mais altos do que os femininos. [...] $\bigcirc$ maior medo do homem e da mulher é não satisfazer o(a) parceiro(a). Maior até que o medo de contaminarse com (Doenças Sexualmente Transmissíveis) DSTs. [...] As mulheres e os homens com dificuldades sexuais tem prejuízo (repercussão) em outras áreas da vida: amor próprio, autoestima, relacionamento em geral com o(a) parceiro(a), trabalho, lazer, passeios, relacionamento com os filhos, relacionamento social. (pp. 51-52)

Segundo Abdo (2004) "Acredite! Segundo essa pesquisa o grau de importância do sexo na vida do nosso povo equivale a 'ter uma fonte de renda segura', a 'conseguir respirar' ou a 'tirar férias todos os anos'." (p. 56)

A vida interna tem seu caminho e seu tempo: a busca de soluções imediatas para os problemas, o uso de remédios, por exemplo, não garante que haverá satisfação e, mesmo que o resultado físico será positivo; a alma parece nunca deixar de criar desassossego.

Nosso corpo é o concreto, o visível, o lugar onde tudo pode se revelar literalmente. Uma atração sexual é sentida no corpo, mas não é somente um evento físico. Ali também está a psique, especialmente o inconsciente, que tem seus desejos e intenções. $\bigcirc$ que imaginamos ser a nossa intenção ou arbítrio é, em última análise, a intenção do nosso ego. Mas, por detrás desta intenção reconhecida, atua algo muito poderoso, o inconsciente, especialmente os conteúdos do inconsciente coletivo, e o ego tem grande dificuldade em aceitar isso, o que gera uma separação de corpo, psique e espírito: cada um sendo observado separadamente, criando uma divisão psíquica na qual o corpo passa a ser o portador e a expressão da neurose que é gerada pelo conflito. $O$ corpo separado da psique se torna um estranho para nós. E assentados nessa estranheza, como nos relacionarmos com o outro e com o corpo do outro? Essa divisão impossibilita a entrega. Como me dar se não consigo me reconhecer na minha própria divisão?

Atualmente, somos governados pela eficiência e, em busca da eficiência, às vezes nos cegamos para a sensibilidade do nosso corpo e do que ele nos comunica. Nossa era se acha marcada pela produtividade: nossa vida e nosso corpo têm que ser produtivos e, como máquinas, não podemos falhar, o que gera uma ansiedade que se enraíza na vida em geral e na vida sexual 
em particular. $O$ prazer precisa acontecer de forma balanceada, pois, o seu excesso ou escassez abrem caminho para a sombra, que se revelará na disfunção, trazendo para a pessoa uma sensação de fracasso. Segundo Moore (1994): "Sem entender a alquimia do fracasso, há uma boa chance de nunca sermos bem-sucedidos." (p. 177) Se, de alguma forma, há uma perda ou ruptura entre a vida e a profundidade psíquica, o sintoma e o fracasso são o único caminho para o indivíduo percorrer.

O sexo é alimento da alma. Cada orgasmo é uma pequena morte, como costumam dizer os franceses. É preciso aceitar o seu poder de nos atrair e também de nos perturbar. Nele estão embutidas as vivências tanto do prazer quanto do fracasso, que podem nos levar a formas destrutivas de viver, pois possuem uma linha muito tênue entre o saudável e o obsessivo.

Todos temos aptidão para nos vincularmos ao nosso lado escuro: e o sexo pode abrir portas bem largas para isso. A psique, enquanto natureza, não se importa por onde caminhamos quando a sua meta é a realização da sexualidade. Para tanto, forças inconscientes poderão incluir o mais profundo submundo nas nossas vidas em busca da sua realização. A repressão religiosa, por exemplo, ao direcionar ao corpo um olhar desaprovador e, eventualmente ver o sexo como demoníaco, estimula aquilo que quer reprimir: sintomas sexuais e perversões. Moore (1999) conta um fato que expressa essa repressão: "Nos mosteiros, os copistas costumavam preencher as margens vazias dos livros com fortes linguagens e imagens sexuais. Essas margens eram conhecidas como sarjetas." (p. 443) A sexualidade é colocada literalmente na sarjeta. Ainda assim, sintomas e disfunções sexuais representam uma tentativa da psique de nos obrigar a nos perceber e a estarmos abertos à possibilidade de novas fontes de criatividade. Como expõe Heinrich Zimmer (1999): "A função da malignidade é manter em funcionamento a dinâmica da transformação. $O$ mal deve ser aceito e assimilado, não evitado." (p. 39) A cura, seja de uma disfunção sexual, seja de outro problema qualquer, passa por agir de forma criativa perante estes problemas ou disfunções, assumindo a reponsabilidade pelo que está acontecendo nesse momento e entrando na vida ao aceitar os desafios que ela impõe.

Para isso, temos que abrir mão de uma vida estática, aceitar o que nos assusta, o movimento da alma, o imaginal, e abandonar a segurança e, principalmente, a tentativa fantasiosa de controle exclusivamente racional. Somos levados pela cultura a pensar que um problema deve ser resolvido apenas pela mente racional. Esquecemos que outras coisas envolvem este problema. Deixamos de lado emoções, valores, pensamentos, visão, influências, paixões que, com frequência, interferem e muitas vezes são responsáveis pelo problema que se apresenta. Abrir mão da nossa inconsciência, que nos dá certo conforto, dá muito trabalho afinal. $\mathrm{Na}$ disfunção sexual algo foi deixado de lado e se voltou contra a própria pessoa. Quando o diálogo interno é retomado, o problema pode ser visto de forma criativa e construtiva. $\bigcirc$ que o sintoma pede é um ajuste da vida. Nossas vidas estão separadas dos nossos instintos e da natureza. A vida 
intensa nos afasta do contato com o nosso lado físico. O sexo no seu lado instintual é também natureza agressiva, Marte e Afrodite: por um lado, virilidade e força masculina de penetração, por outro, suave harmonia feminina de receber. Quando essas duas forças se veem separadas, a dificuldade, seja feminina, seja masculina, aparece. $\bigcirc$ que o sexo precisa é o primitivo, o instintual e o espontâneo. Ao nos afastarmos do lado instintual do sexo, o banalizamos, perdemos o seu lado misterioso. Procuramos estudá-lo com minúcias e tanto mais ele se oculta. Na verdade, não temos conhecimento da profundidade de suas raízes na alma ou qual é seu lugar definitivo na vida.

\section{Considerações finais}

Toda a disfunção nada mais é do que um lembrete. Uma tentativa de fazer com que olhemos como está nossa vida. É uma chamada para reavaliarmos o que estamos fazendo ou deixando de fazer e, com isso, possibilitar que coisas em nós possam morrer e renascer com outra história e outros significados.

Atenção e foco são também qualidades das quais precisamos, pois são instrumentos fundamentais para a transformação. Nada como uma dor física para percebermos o que de errado está acontecendo no corpo, e nada como uma dor emocional para podermos nos focar onde é necessária a transformação. $O$ indivíduo que apresenta um sintoma deseja se livrar do incômodo e muito rapidamente percebe que este está grudado como cola. Mero entendimento ou força de vontade não são suficientes. A disfunção tem raízes profundas: enquanto a transformação não acontecer, o sintoma persistirá. Enquanto a pessoa permanecer cega para o que a alma quer, terá que se haver com esse incômodo.

Se o problema está instalado, dividir a questão com o(a) parceiro(a) possibilita encontrar uma forma de conduzi-lo. A intimidade facilita o ajustamento relacional. Um companheirismo solidário pode não trazer a cura, mas estreita os laços. Ficar mais próximo nesse momento ajuda a trabalhar a fantasia sobre a disfunção e, com isso, abre-se uma porta para se perceber o que cada um depositou na relação. $O$ que estava sem vida, sem alma, se torna aquecido e Eros pode retornar. A ansiedade que tomava conta da relação pode ser aliviada, pois se cria um significado para o momento. É necessário respeitar as dificuldades que um relacionamento traz consigo. Somos diferentes uns dos outros. Então, a intimidade gratificante tem de admitir que o sexo possa sofrer vários ferimentos a partir dessas diferenças. Descobrir a interioridade da relação e se encantar com ela é o caminho para a cura. Quando a pessoa passa a ter um genuíno interesse por si e pelo outro, surge a oportunidade de compreender o que a alma fala por meio de todas as imperfeições, descaminhos, acertos e erros - a pessoa como ela é, nua diante da vida, passando por uma peneira os valores recebidos e conservando apenas o que diz respeito a si mesma: o que Jung denomina individuação. 
O trabalho com a psique requer tempo, é um processo em que a história da disfunção tem que ser desvelada na história do paciente - a história que está sendo encenada, os padrões familiares, sociais e religiosos que fazem parte da encenação, o mito ao qual esse indivíduo se entrega. Quanto menos se tem ciência disso, mais se interpreta uma peça da qual não possuímos o script. $\bigcirc$ sexo dentro desta peça não encontra a tranquilidade e a criatividade que possibilitam um resultado mais satisfatório.

O sexo tem em si a atração e o prazer mútuos que nos colocam em contato com o outro. Devemos encarar uma disfunção sexual como um mistério que ali está para nos manter fazendo perguntas, apontando direções, confundindo-nos e pondo à prova a nossa inteligência, e, no final, sempre nos surpreendendo. Estamos na maioria das vezes tão interessados em explicações que não percebemos o quanto nos colocamos imunes ao poder transformador que a disfunção exige. A disfunção é um aprisionamento, uma raiva que se volta contra o próprio indivíduo. Tratamos a pessoa e sua disfunção com ações que abrandam a rigidez e a secura. Tentamos ajudá-la para que o problema não seja encarado na sua concretude, mas sim no seu aspecto simbólico. Se restaurada como princípio maduro de vida, a sexualidade adquire novo sentido. É necessário que Eros surja, pois ele é o interlocutor entre a alma e a sexualidade, envoltas em prazer e encantamento. Se a alma permanecer adormecida, a nossa vida também se encontrará parada. "Estar na alma" pode ser um processo doloroso, cheio de desmembramentos e mortes, mas há nele a possibilidade de transformar nossas vidas.

\section{Referências}

Abdo, C. (2004). Descobrimento sexual do Brasil. São Paulo: Summus.

Jung, C. G. (2002). Estudos alquímicos. In C. G. Jung, Obras Completas (Vol. XIII. D. M. R. F. Silva, M. L. Appy, trads.). Petrópolis, RJ: Ed. Vozes. Petrópolis. Ed. Vozes.

Jung, C. G. (2013). O livro vermelho - Liber novus. Petrópolis: Editora Vozes.

Master, W. H., Johnson, V. E., Kolodny, R. C. (1997). Heterossexualidade. Lisboa: Editora Bertrand Brasil.

Moore, T. (1994). Cuide de sua alma. São Paulo: Siciliano.

Moore, T. (1996). O que são almas gêmeas? Rio de Janeiro: Ediouro.

Moore, T. (1999). A emoção de viver a cada dia. Rio de Janeiro: Ediouro.

Moore, T. (2009). Escrito na areia. São Paulo: Prumo.

Zimmer, H. (1999). A conquista psicológica do mal. São Paulo: Palas Athena. 
O falar da alma nas disfunções sexuais | Marisa H orta Imperatrice

Minicurrículo: Marisa Horta Imperatrice - Psicóloga. Analista do Instituto Junguiano de São Paulo (IJUSP); membro da Associação Junguiana do Brasil (AJB); filiada à International Association for Analytical Psychology (IAAP/Zurich). E-mail:mhimperatrice@yahoo.com.br 